\title{
Identification and characterisation of 17 polymorphic candidate genes for response to parasitic nematode (Trichostrongylus tenuis) infection in red grouse (Lagopus lagopus scotica)
}

\author{
Marius A. Wenzel ${ }^{1 *}$, Lucy M.I. Webster ${ }^{1,2}$, Steve Paterson ${ }^{3}$ \& Stuart B. Piertney ${ }^{1}$
}

August 20, 2014

${ }^{1}$ Institute of Biological and Environmental Sciences, University of Aberdeen, Zoology Building, Tillydrone
Avenue, Aberdeen AB24 2TZ, UK
${ }^{2}$ Current address: Science and Advice for Scottish Agriculture, Roddinglaw Road, Edinburgh EH12 9FJ, UK
${ }^{3}$ Institute of Integrative Biology, University of Liverpool, Liverpool L69 7ZB, UK
* corresponding author. email address: marius.a.wenzel.08@aberdeen.ac.uk. Phone number: +44 1224272395

Word counts: 143 (abstract), 777 (main text), 92 (table legends)

Keywords: red grouse; Lagopus; parasite; candidate genes; adaptive genetic diversity; population genomics

\begin{abstract}
The red grouse (Lagopus lagopus scotica) is an economically important game bird species endemic to the upland heather moors of the British Isles, where its conservation status is "amber" due to long-term declines in breeding populations. One major driver of grouse population ecology is chronic infection by the highly prevalent, gastrointestinal parasitic nematode Trichostrongylus tenuis. Here, we outline the identification and characterisation of 17 candidate genes for the physiological response of red grouse to parasite infection, developed de novo from functional and genetic analysis of grouse transcriptomic and genomic resources. These genes capture broad physiological functions, including immune system processes, xenobiotics detoxification, oxidative balance, metabolism and cell cycle regulation. All genes were polymorphic at the landscape scale in north-east Scotland, indicating great utility for characterising the causes and consequences of spatio-temporal genetic variation in relation to parasite-mediated eco-evolutionary processes in red grouse populations.
\end{abstract}

An increasingly important aspect of conservation practice is the effective management of adaptive genetic diversity in natural populations (Ouborg et al, 2010). However, the identification of appropriate genomic regions that directly relate to traits influencing individual fitness and population viability has proven a major challenge (Allendorf et al, 2010). Here, we describe a strategy for the "top-down" identification (sensu Piertney and Webster, 2010) of novel polymorphic candidate genes from transcriptomic and genomic resources. Specifically, we identify 17 candidate genes for red grouse (Lagopus lagopus scotica Lath.) that are directly related to interactions with the highly prevalent parasitic nematode Trichostrongylus tenuis Mehlis (Wilson, 1983; Shaw and Moss, 1989). Chronic infection by this parasite substantially impacts grouse condition, survival and fecundity (Hudson, 1986; Watson et al, 1987; Hudson et al, 1992; Delahay et al, 1995), with negative consequences for population dynamics and long-term population viability (Hudson et al, 1998; Redpath et al, 2006; Martínez-Padilla et al, 2014).

Transcriptome libraries for caecum, spleen and liver were prepared from grouse either experimentally infected with T. tenuis larvae or treated with an anthelmintic (Webster et al, 2011a). Using suppression subtractive hybridisation (SSH), libraries were enriched for transcripts present in infected birds only (Webster et al, 2011a). 
Clone sequences of enriched (SSH) and non-enriched (standard cDNA) libraries were used to construct a microarray for assaying differences in caecal gene transcription levels among grouse with natural parasite loads, experimental infection or anthelmintic treatment (Webster et al, 2011b). Based on gene product identity and function (Blastx and GENEONTOLOGY; Webster et al, 2011a,b), 578 clone sequences (447 Kbp) were then used to construct a genomic capture array (Paterson et al., unpublished) for identifying population-level genetic polymorphisms (SNPs) in two red grouse populations (Catterick, England and Edinglassie, Scotland) that differ in typical parasite load, and one willow grouse (L. l. lagopus) population from Sweden. Hybridised genomic DNA was pyrosequenced and reads were assembled to contigs. Polymorphic sites in each contig were identified (coverage $\geqq 30$ and $\geqq 6$ variant reads) and pairwise genetic differentiation $\left(F_{\mathrm{ST}}\right)$ among the three populations was calculated and tested for statistical significance by permutation.

Candidate contigs had to satisfy at least one of four criteria: 1) expressed in infected red grouse only (SSH libraries); 2) significantly differentially regulated $(p<0.05)$ among red grouse with different parasite loads; 3 ) significantly genetically differentiated $\left(F_{S T}>0 ; p<0.05\right)$ among red grouse populations with different parasite loads (candidate for directional selection); or 4$)$ not significantly differentiated $\left(F_{S T} \geq 0 ; p>0.05\right)$ among red grouse populations but at least weakly $\left(F_{S T}>0\right)$ among red and willow grouse (candidate for balancing selection). The functional categories of the selected candidates included immune system processes, xenobiotics detoxification, oxidative balance, metabolism and cell cycle regulation, capturing a broad physiological response to parasite infection (Table 1).

The cDNA clone sequence of each candidate contig was mapped to the chicken genome (Gallus gallus galGal4 assembly) using BLAT (Kent, 2002) to identify exonic genomic regions. Associated grouse genomic contigs were mapped to the identified chicken chromosome regions in Geneious v5.6.3 (Drummond et al, 2012). Primers were then designed on those genomic contigs, using PRIMER3 (Rozen and Skaletsky, 2000) as implemented in GENEIOUS, so that a 120-600 bp amplicon would be at least partially exonic and include at least one polymorphic exonic site. Cross-species utility of the primers was tested using IN SILICO PCR (Hinrichs et al, 2006) on chicken (Gallus gallus galGal4 assembly), turkey (Meleagris gallopavo melGal1 assembly) and zebrafinch (Taeniopygia guttata taeGut1 assembly) genomes.

Levels of polymorphism were ascertained in three red grouse individuals from locations that maximise geographic variation across a landscape of grouse moors in north-east Scotland (Glenlivet $57.29{ }^{\circ} \mathrm{N} 3.18{ }^{\circ} \mathrm{W}$, Mar Lodge $56.95{ }^{\circ} \mathrm{N} 3.66^{\circ} \mathrm{W}$ and Invermark $56.89^{\circ} \mathrm{N} 2.88^{\circ} \mathrm{W}$ ). PCRs were carried out in a total volume of $25 \mu \mathrm{l}$ containing $\sim 25 \mathrm{ng}$ DNA template, $10 \mathrm{mM}$ Tris- $\mathrm{HCl}, 50 \mathrm{mM} \mathrm{KCl}, 2.5 \mathrm{mM} \mathrm{MgCl} 2,0.2 \mathrm{mM}$ of each nucleotide, $0.5 \mu \mathrm{M}$ of each primer and $0.625 \mathrm{U}$ Taq DNA Polymerase (Sigma-Aldrich). PCR profiles consisted of initial denaturation at $95{ }^{\circ} \mathrm{C}$ for $2 \mathrm{~min}, 35$ cycles of denaturation at $95{ }^{\circ} \mathrm{C}$ for $30 \mathrm{~s}$, annealing at locus-specific temperatures (Table 2) for $30 \mathrm{~s}$ and elongation at $72{ }^{\circ} \mathrm{C}$ for $30 \mathrm{~s}$, and final elongation at $72{ }^{\circ} \mathrm{C}$ for $5 \mathrm{~min}$. In TouchDown profiles (Don et al, 1991), the annealing temperature was decreased by $0.5{ }^{\circ} \mathrm{C}$ per cycle for the first 20 cycles (Table 2). Amplicons were purified using a QIAQUICK PCR Purification Kit (Qiagen) and Sanger-sequenced using the forward primer on an ABI 3730xl sequencer (Eurofins MWG, Ebersberg, Germany). Sequences were aligned in GENEIOUS and heterozygote sites were coded as IUPAC degenerate bases. Polymorphic sites, numbers of haplotypes, nucleotide diversity, haplotype diversity and Tajima's $D$ (neutrality test) were then computed on reconstructed haplotypes (PHASE method) in DNASP v5 (Librado and Rozas, 2009).

Twelve genes amplified in silico in at least one bird model, demonstrating a degree of cross-species utility (Table 2). Polymorphism ranged from 1-13 SNPs and 2-4 haplotypes per gene (haplotype FASTA file available in electronic supplementary materials), with evidence for departure from neutrality in gene Lls_CG06 (Table 2). These genes provide a valuable resource for exploring spatio-temporal patterns of genetic variation in relation to parasite-mediated eco-evolutionary processes in red grouse populations (Table 2). 


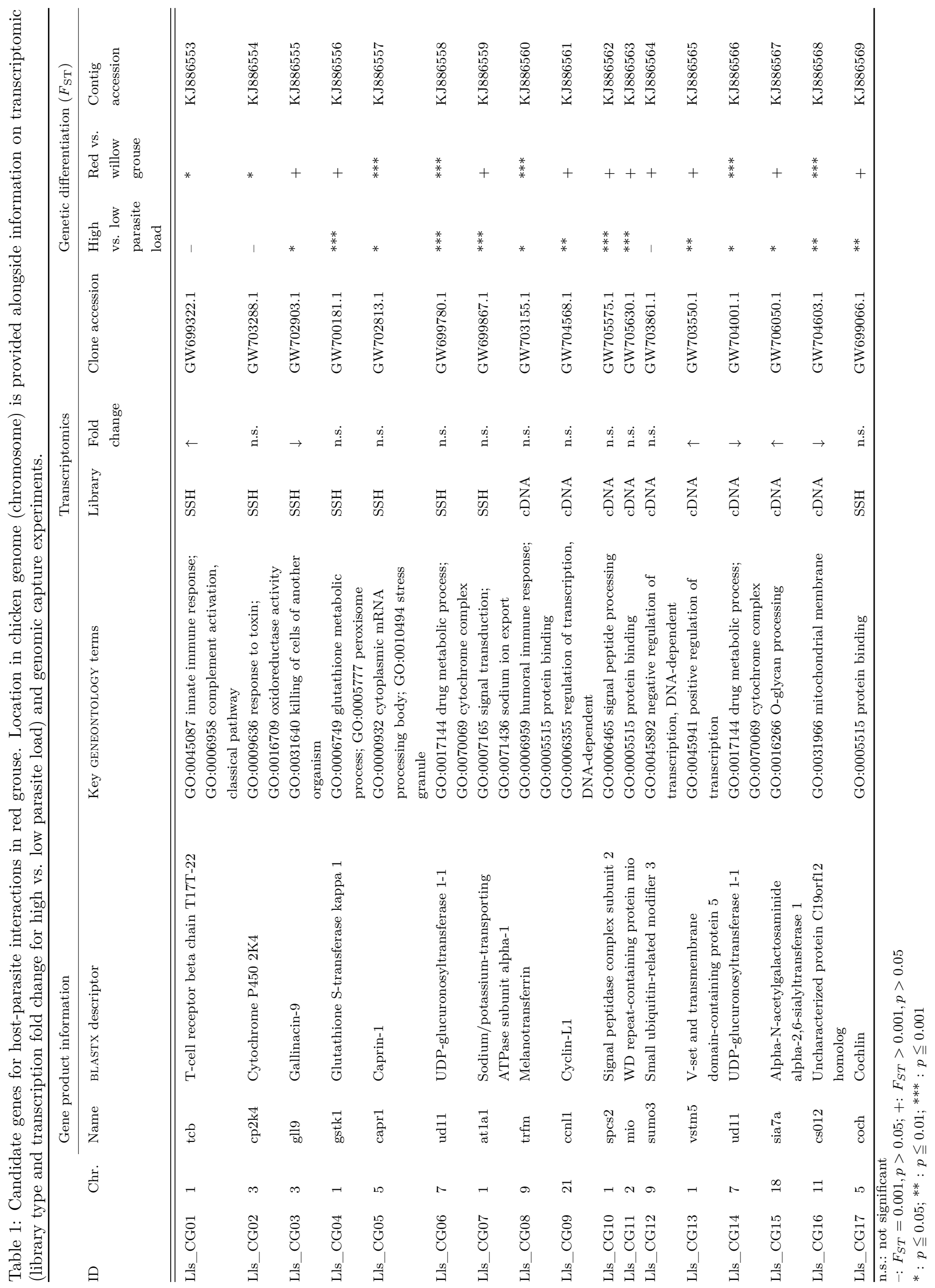




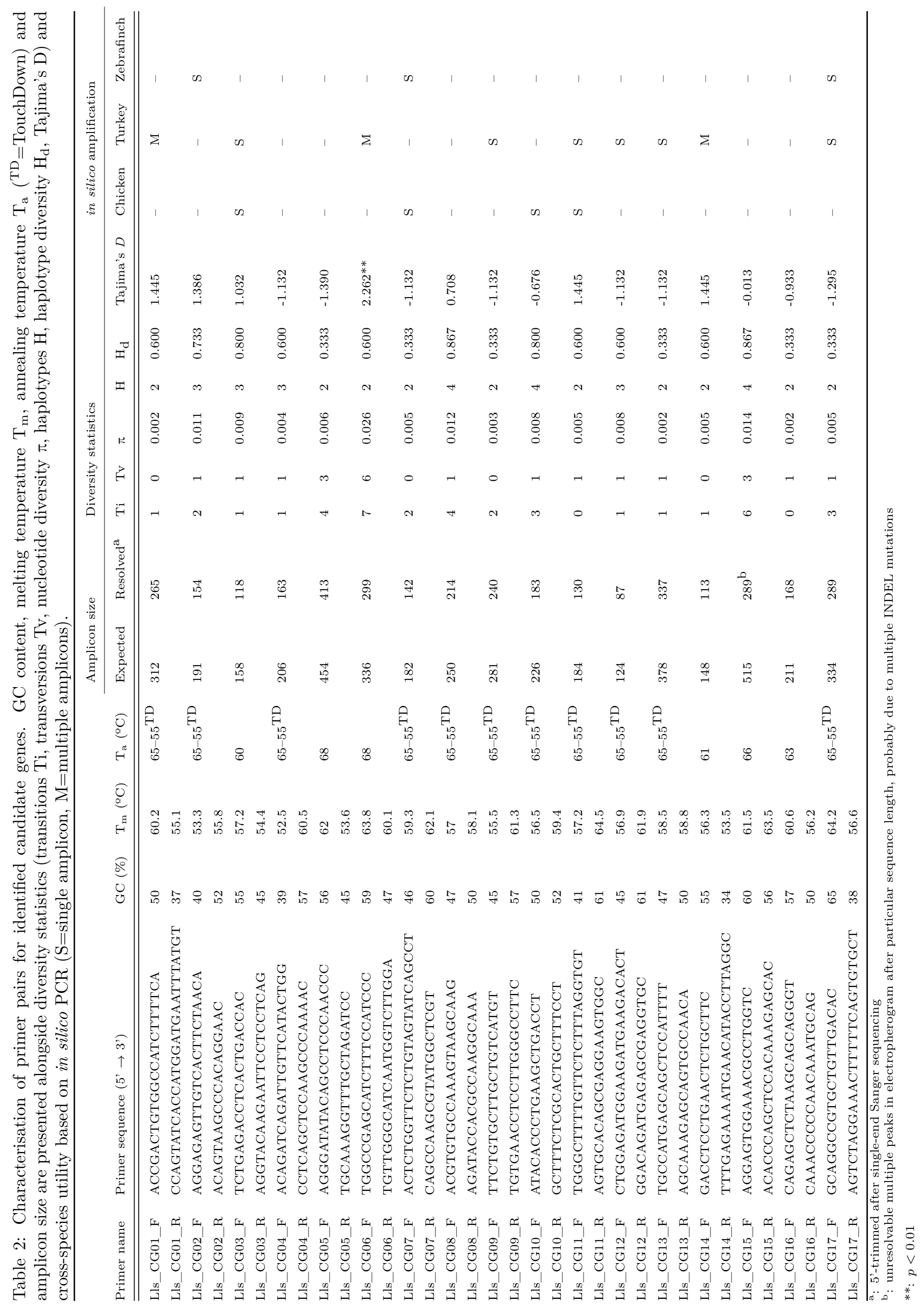




\section{Acknowledgements}

This study was funded by a BBSRC studentship (MA Wenzel) and NERC grants NE/H00775X/1 and NE/D000602/1 (SB Piertney). We are grateful to Jacob Höglund for providing willow grouse samples, Mario Röder, Keliya Bai, Marianne James, Matt Oliver, Gill Murray-Dickson, François Mougeot and Jesús Martínez-Padilla for help with fieldwork, and all grouse estate factors, owners and keepers, most particularly Alistair Mitchell, Shaila Rao, Christopher Murphy, Richard Cooke and Fred Taylor, for providing access to estate game larders.

\section{References}

Allendorf FW, Hohenlohe PA, Luikart G (2010) Genomics and the future of conservation genetics. Nat Rev Genet 11:697-709

Delahay RJ, Speakman JR, Moss R (1995) The energetic consequences of parasitism: effects of a developing infection of Trichostrongylus tenuis (Nematoda) on red grouse (Lagopus lagopus scoticus) energy balance, body weight and condition. Parasitology 110(4):473-482

Don R, Cox P, Wainwright B, Baker K, Mattick J (1991) 'Touchdown'PCR to circumvent spurious priming during gene amplification. Nucleic Acids Res 19(14):4008

Drummond A, Ashton B, Buxton S, Cheung M, Cooper A, Duran C, Field M, Heled J, Kearse M, Markowitz S, Moir R, Stones-Havas S, S S, Thierer T, Wilson A (2012) Geneious v5.6.3. Available from http://www.geneious.com

Hinrichs AS, Karolchik D, Baertsch R, Barber GP, Bejerano G, Clawson H, Diekhans M, Furey TS, Harte RA, Hsu F, et al (2006) The UCSC genome browser database: update 2006. Nucleic Acids Res 34(suppl 1):D590-D598

Hudson PJ (1986) The effect of a parasitic nematode on the breeding production of red grouse. J Anim Ecol $55(1): 85-92$

Hudson PJ, Dobson AP, Newborn D (1992) Do parasites make prey vulnerable to predation? Red grouse and parasites. J Anim Ecol 61(3):681-692

Hudson PJ, Dobson AP, Newborn D (1998) Prevention of population cycles by parasite removal. Int S Techn Pol Inn 282:2256-2258

Kent WJ (2002) BLAT-The BLAST-Like Alignment Tool. Genome Res 12:656-664

Librado P, Rozas J (2009) DnaSP v5: a software for comprehensive analysis of DNA polymorphism data. Method Biochem Anal 25(11):1451-1452

Martínez-Padilla J, Redpath SM, Zeineddine M, Mougeot F (2014) Insights into population ecology from longterm studies of red grouse Lagopus lagopus scoticus. J Anim Ecol 83(1):85-98

Ouborg NJ, Pertoldi C, Loeschcke V, Bijlsma RK, Hedrick PW (2010) Conservation genetics in transition to conservation genomics. Trends Gen 26(4):177-187

Piertney SB, Webster LMI (2010) Characterising functionally important and ecologically meaningful genetic diversity using a candidate gene approach. Genetica 138:419-432

Redpath SM, Mougeot F, Leckie FM, Elston DA, Hudson PJ (2006) Testing the role of parasites in driving the cyclic population dynamics of a gamebird. Ecol Lett 9(4):410-418

Rozen S, Skaletsky HJ (2000) Primer3 on the WWW for general users and for biologist programmers. Meth Mol Biol 132:365-386 
Shaw JL, Moss R (1989) Factors affecting the establishment of the caecal threadworm Trichostrongylus tenuis in red grouse (Lagopus lagopus scoticus). Parasitology 99(2):259-264

Watson H, Lee DL, Hudson PJ (1987) The effect of Trichostrongylus tenuis on the caecal mucosa of young, old and anthelmintic-treated wild red grouse, Lagopus lagopus scoticus. Parasitology 94(2):405-411

Webster LMI, Mello LV, Mougeot F, Martínez-Padilla J, Paterson S, Piertney SB (2011a) Identification of genes responding to nematode infection in red grouse. Mol Ecol Res 11(2):305-313

Webster LMI, Paterson S, Mougeot F, Martínez-Padilla J, Piertney SB (2011b) Transcriptomic response of red grouse to gastro-intestinal nematode parasites and testosterone: Implications for population dynamics. Mol Ecol 20(5):920-931

Wilson GR (1983) The prevalence of caecal threadworms (Trichostrongylus tenuis) in red grouse (Lagopus lagopus scoticus). Oecologia 58:265-268 